\title{
Environmental Stressors and their Impact at Work: The Role of Job Stress Upon General Mental Health and Key Organisational Outcomes across Five Occupational Groups
}

\author{
Saqib Saddiq ${ }^{1}$ and Zaffer Iqbal ${ }^{2,3 *}$ \\ ${ }^{1}$ Business Psychologists Ltd, Huddersfield UK \\ ${ }^{2}$ Faculty of Health Sciences, University of Hull, Hull UK \\ ${ }^{3}$ Navigo CiC,3 Brighowgate, Grimsby, UK
}

Submission: March 16, 2019; Published: April 15, 2019

*Corresponding author: Zaffer Iqbal, Navigo CiC, 3 Brighowgate, Grimsby, UK

Abstract

The study explored the validity of Warr's [1,2] nine-environmental stressors' questionnaire across a sample of employees from five occupational categories (police service, fire service personnel, school teachers, train drivers and related personnel, and librarians) varying in the stressful nature of their work duties. The association between perceived occupational stress and absenteeism, psychological health, job satisfaction, and family stress was also examined. A survey-based questionnaire approach was employed. It was predicted that high reported stress would be characterised by poor job satisfaction, greater unofficial absenteeism, psychological disturbance and greater work-family stress. All hypotheses were supported. However, the results for the unofficial absenteeism analysis was concluded to be anecdotal as the measure failed to fulfil basic statistical assumptions and was possibly confounded by a response bias. Warr's measure was found to have high reliability, and the use of factor analysis coupled with parallel analysis, categorised Warr's 9 stressors into a clearly defined 6-factor solution. The outcomes of the study and their implications are discussed, and future recommendations for methodology and also for further investigations are made.

\section{Introduction}

Since the 1950's, the topic of occupational stress has become of increasing importance within industry [2-5]. Most of the research has concentrated on the causes of such stress, but there has also been an interest in the provision of possible remedies for the elimination or control of specific stressors (for a review see [6]). Indeed, controlling stress is believed to be a key aspect in improving employee performance.

This link between psychological well-being and occupational stress has received extensive investigation within the literature [7-10]. Elkin \& Rosch's [11] review indicates that 54\% of employee absence in the US industry was stress-related and, the Confederation of British Industry (CBI) report that over $£ 4$ billion is lost annually, in the UK, through stress-related sickness [12].

\section{Warr's $(1987,1994)$ Nine Environmental Stressor's}

Although several researchers have focussed upon specific variables deemed to impact upon work-related stress, few have attempted to provide an "all-encompassing" theoretical explanation. A prominent example of the latter is provided by Warr
[7], who as a precursor to the development of a nine-factor theory of job-related well-being, outlined several key components of job satisfaction in two broad inter-correlated areas: intrinsic and extrinsic factors. Intrinsic factors concern "features inherent with the conduct of the job..." such as "opportunity for personal control and skill utilisation, amount of task variety and so on", whereas extrinsic factors concern "aspects that form a background to the work itself..." such as "satisfaction with pay, working conditions, job security, and industrial relations procedures...".

The nine-factors for job-related well-being proposed by Warr $[1,2]$ are as follows:

i. Opportunity for personal control or autonomy,

ii. Opportunity for skill use,

iii. Externally generated goals or job demands or workload,

iv. Variety in job content, location and skill use,

v. Environmental clarity in terms of feedback and the unambiguous provision of information, 
vi. Opportunity for interpersonal contact in terms of social support, communication with others and privacy when required,

vii. Availability of money, viii. Physical security or the provision of safe, healthy work environments, and

ix. Valued social position or occupational prestige, within society, the organisation and on a personal level.

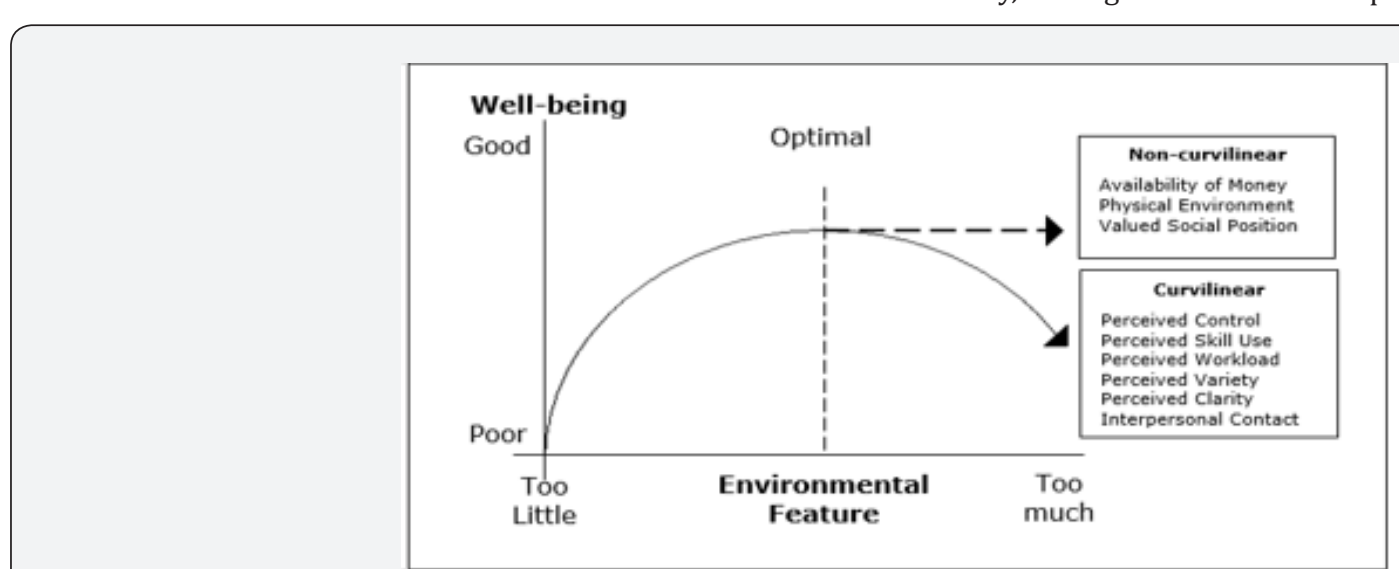

Figure 1: Suggested relationships between environmental stressors and well-being [2].

These factors were formulated into an environmental stressors questionnaire, which has enjoyed some success within industry [13]. The questionnaire assesses perceived stress of individuals based on environmental stressors. Warr suggested a curvilinear relationship between the first 6 factors (Figure 1), where too much or too little could lead to poor well-being with an optimum level required for good well-being. The last 3 factors, those of money, environment and valued social status, only followed a curvilinear relationship initially, where too little could prove problematic, but too much maintained optimal well-being.

\section{Implications of Work-Related Stress}

The typical consequence of work-related stress appears to be psychological disorder. For example, work-related stress has also been linked to depressive disorder $[10,14]$. It is accepted that work and family are two areas that are vital in providing satisfaction in an individual's life, but yet they are both sources that induce stress. Tennant and also Theorell et al.'s papers outline the major implications of work-related stress (distress) including worker dissatisfaction, mental health, absenteeism and the wider impact on family function. An overview of these is presented below.

\section{Psychological Health and Stress}

Investigation of occupational stress and wellbeing has focussed primarily on stressors in the workplace that may act as risk factors for mental illness, and whether self-report measures of stress, such as the General Health Questionnaire [15] are congruent with the onset of such a reactive disorder. For example, Cieslak et al. [16] demonstrate how secondary traumatic stress is linked to burnout amongst professionals working with trauma survivors. Although a lack of stress does not seem plausible, since a moderate amount is required to keep the employee motivated, Fletcher [17], amongst others, argues that too much can lead to many psychological and even physical health problems, as well as a diminished level of work performance.

\section{Environmental Stressors and Job Satisfaction}

Research has suggested several aspects affecting job satisfaction, including those within the individual's control such as workload, job stress including physical and mental health, and occupational rewards [18]. The importance of job satisfaction (distress) is highlighted in the findings of Zani \& Pietrantoni [19] who found that work dissatisfaction with regards to social relationships (a work stressor) was the most apparent outcome of burnout in hospital-based staff. Indeed, it is well accepted that job satisfaction is linked with routine work stressors [20]. Role conflict, a wellknown job stressor, was found to intensify the level of burnout and job dissatisfaction [5], and Schonfield [21] emphasises serious depressive problems and decreased job satisfaction for teachers who were exposed to poor working environments. Earlier work by Schaefer \& Moos [22] found that individuals who experienced higher levels of work stress reported more job dissatisfaction and had less retentive (stay with organisation) intentions. Clearly there appears to be a detrimental effect for the organisation where job satisfaction is poor, as this could lead to a higher staff turnover coupled with a poorer ability to retain staff. Ganster \& Rosen's [4] review of how workplace experiences affect well-being provides a model of how physiological impacts of work stress and well-being can be postulated as load processes, leading to a cumulative effect of primary (stress, anxiety), secondary (blood pressure, body mass index) and tertiary (depression, cardiovascular disease) health problems.

Other factors that may affect work performance have also been suggested. Guppy \& Rick [23] argue that gender and work complexity are significant predictors of job satisfaction. There have been claims that a "social buffer" exits as a moderator between stressors and job satisfaction [5] and it seems likely that 
social support, including family life, may hold vital qualities which help individuals reduce or "buffer" the stressful effects of work.

\section{Environmental Stressors and Absenteeism}

Absenteeism is another problem that many organisations experience, which can prove detrimental not only financially but also in relation to the organisation's performance as a whole. Absenteeism usually stems from job strain [24] and it is of clear importance to organisations to determine which aspects trigger this "distress" reaction and how to tackle these. The mechanisms are complex due to the myriad of variables involved, but stress in the workplace appears to manifest itself through ill health (mental and physical) as a consequence of work difficulties such as job dissatisfaction, staff turnover, poor productivity and of course, absenteeism [25]. Neubauer [26] found that individuals, who reported less stress and lower workload, were likely to report more job satisfaction and less ill health. Those individuals, who reported high levels of absenteeism were likely to be older, working evening shifts (leading to a possible lack of opportunity for social and leisure activity outside the workplace), and reported their work environments as high in stress. They further claimed they had little control over their work.

Absenteeism has also been linked to job insecurity [27], a stressor variable incorporated in Warr's environmental stressors questionnaire, and according to Vasse, Nijhuis \& Kok [28] the levels of work stress have been found to mediate the relationship between other stressors and sickness absence. Jacobson et al. [29] found significant relationships between high perceived stress and self-reported absenteeism for both males and females, with females reporting greater absenteeism levels when highly stressed. It appears that high absenteeism is indicative of individuals with greater perceived stress and poor psychological health.

\section{Environmental Stressors and Work to Family conflict}

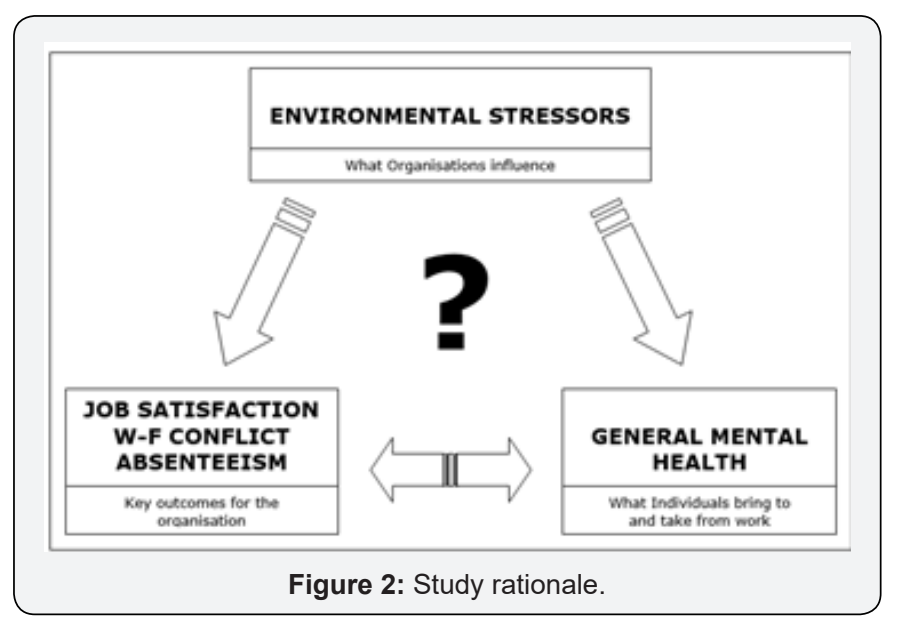

Consideration should also be given to the literature investigating the relationship between work-family overspill and work stress. Work overspill into other areas of the individual's life, usually family, may lead to psychological distress as this significantly affects psychological health [30], job and life satisfaction, staff turnover and commitment to work [31]. Indeed, family acts as a type of social buffer, which may allow individuals to cushion or dampen the effects of work stress. It would therefore be worthwhile to further investigate the relationship between high-perceived stress at work and its effects upon family.

Building on Tenant's work, the study investigated the relationships between three sets of variables (Figure 2):

a. Environmental stressors - Aspects which organisation influence

b. General mental health - What individuals may bring to and take from work

c. Key outcomes (for the organisation) - In terms of three outcomes that are important to the organisation, namely job satisfaction, work-family conflict and absenteeism.

In exploring these sets of variables, we investigated the:

i. Impact of Stressors upon key outcomes of absenteeism, job satisfaction and work-family conflict

ii. Impact of Stressors upon the employee's general mental health

iii. Dyadic relationship between general mental health and key outcomes

\section{Hypotheses}

i. It was predicted that those reporting greater difficulties with environmental stressors would report lower Job Satisfaction, greater Absenteeism and greater Work-Family conflict, with poorer general mental health; and vice versa.

ii. Those with poor general mental health would also report lower Job satisfaction, greater Absenteeism and greater Work-family conflict. Furthermore, we would observe a dyadic relationship in that poorer "key outcomes" such as job satisfaction, work-family conflict and absenteeism would also impact upon an individual's general mental health.

Thus, in the main, the study aimed to develop a practical model that depicted the relationships between these variables, one which could prove useful in resolving certain performance problems, such as the key outcomes, in organisations.

\section{Method \\ Design}

The study employed a between-subjects design, with independent variables of occupation type and psychological health (GHQ). Different occupations were selected based upon variations in the demanding and stressful nature of their work duties. The dependent variables were the perceived environmental stressors, outcomes that were important to the organisation measured in terms of: (1) job satisfaction (global measure), (2) Work to family stress and (3) Absenteeism. 


\section{Participants}

Utilising a medium effect size with an alpha level of .05, and power of .95, a priori power analysis was performed to determine a statistically adequate number of participants required for this study. In total, 292 participants were recruited from 26 out of the 306 organisations approached. The subject groups were selected in terms of their apparent variation in stressful work duties. 5 occupational groups were considered: Police service (high work stress), Fire service (high work stress), Schoolteachers (intermediate work stress), Train drivers and personnel (intermediate work stress), and Librarians (low work stress). Public organisations were contacted due to the high levels of media coverage on stress in these occupations and also issues associated with pay that were apparent at the time. Positive responses were received from 10 of the 61 Fire services approached (99 participants), 7 out of 66 Police services (117 participants), 2 out of 75 Schools (18 participants), 1 out of 50 Railway companies (14 participants), 6 out of 54 Library services (44 participants). The major reason given for a refusal to participate was that similar surveys had recently been conducted within the organisation. Participants were recruited from a variety of geographical areas across the United Kingdom.

The age of participants across the five groups ranged from 18 to 64 years, with an overall mean of 40.65 years. 203 of the participants were married, 64 single, 23 divorced and 2 widowed. The majority of the participants were male (208), in comparison to 84 females, although this finding was not surprising given that the police and fire service employees are predominantly male.

\section{Materials}

A basic demographic sheet was utilised for participants to state their age, gender, marital status and number of hours worked per week (including work done at home) as another indicator of actual "workload" to correspond with Warr's "perceived workload" factor.

\section{Absenteeism Measure}

Unofficial absenteeism was assessed utilising a three-item measure, which was employed and validated by the University of Surrey Psychology department. The measure has a typical reliability of approximately 0.7 (Hair, personal communication) and the items required a simple "yes" or "no" answer. A higher score indicated greater Absenteeism.

\section{Work-Family Stress' Measure}

Work to Family stress was determined using six Likert style items taken from Carlson, Kacmar and Williams' [32] Work-Family conflict scale. The first three items are indicative of time-based work interference with family, i.e. not having sufficient time with family due to work. The latter three items were "strain based", i.e. being too drained to participate in family activities. Scoring for this scale requires the simple addition of scores. The internal consistency reliability was found to be approximately 0.8 , and the scale was shown to have good discriminant validity [32].

\section{Perceived Environmental Stress Questionnaire}

The perceived environmental stressors (nine-factor) questionnaire [1,2] was employed to assess perceived stress in the workplace on the nine-factors of: perceived control; perceived skill use; perceived workload; perceived variety; perceived clarity; opportunity for interpersonal contact; availability of money; valued social position and physical environment. The instrument consisted of 27 items, each of which required participants to respond to a seven-point 'Likert-type' scale, from "strongly disagree" (1) to "strongly agree" (7). Three questionnaire items defined each factor and factor scores were calculated by summing the scores for these. A higher score was depictive of a greater effect for that that variable. The nine-factor questionnaire has been successfully utilised in the past [13].

\section{General Health Questionnaire}

The GHQ-12 [15] is a 12-item questionnaire that provides a mean score indicative of psychological disorder. Participants were required to respond to each item by circling one of four contingencies: "less than usual", "no more than usual", "rather more than usual" and "much more than usual". Each contingency was scored as $0,0,1$ or 1 respectively, and the sum total for the 12 items provided a total GHQ score. An established cut-off score of 3 was indicated for the scale, and a score equal or higher than this is indicative of psychiatric disorder. The questionnaire has been shown to have high internal consistency, and good reliability (0.87) and external validity $(0.7+)$ with a variety of populations [33].

\section{Job Satisfaction Measure}

Job Satisfaction was measured via the utilisation of a global measure [34] of job satisfaction, consisting of 7 Likert-style items. The scale consists of positive and negative items, with items 2, 3, 5 and 6 reversed. Scoring requires the simple addition of the value for each response. A high score indicated greater job satisfaction. The scale showed an internal consistency reliability of 0.87 and has also shown good validity [34].

\section{Procedure}

Possible organisations that may be willing to participate in the study were identified and approached. Once an agreement was established with an organisation, batches of the questionnaire battery, each comprising a de-briefing letter, demographic sheet, the five questionnaires and a stamped-addressed envelope were forwarded to the organisations, which distributed these amongst their staff. Confidentiality and anonymity were stressed throughout the study. Completed questionnaires were returned to the researchers.

\section{Results}

\section{Sample}

Table 1 below provides a breakdown of response rate by the three occupational groups and also mean values for the demographic data requested. 


\section{Psychology and Behavioral Science International Journal}

Table 1: Depicting demographic information for the five occupations.

\begin{tabular}{|c|c|c|c|c|c|}
\hline \multirow{2}{*}{ Occupation } & \multicolumn{3}{|c|}{ N (\% by occupation) } & \multirow{2}{*}{ Mean age (years) } & \multirow{2}{*}{ Mean weekly Workload (hours) } \\
\cline { 2 - 5 } & Total & Male & Female & & 46.61 \\
\hline Police & 117 & $92(79 \%)$ & $25(21 \%)$ & 38.59 & 49.56 \\
\hline Fire Service & 99 & $84(85 \%)$ & $15(15 \%)$ & 39.45 & 51.64 \\
\hline Train & 14 & $13(93 \%)$ & $1(7 \%)$ & 40.21 & 52.5 \\
\hline Teachers & 18 & $6(33 \%)$ & $12(67 \%)$ & 50.56 & 32.5 \\
\hline Librarians & 44 & $13(30 \%)$ & $31(70 \%)$ & 44.89 & 46.89 \\
\hline Total & 292 & $208(71 \%)$ & $84(29 \%)$ & 40.65 & \\
\hline
\end{tabular}

\section{Age and Occupational Differences}

Differences between the occupational groups, detected using ANOVA, were evident for both age $[\mathrm{F}(4,287)=11.10, \mathrm{p}<.001]$ and weekly workload $[F(4,287)=13.83, p<.001]$. Post-hoc analyses (Tukey) revealed that teachers and librarians were similar in age, although both of these groups were older than the police and fire service $(\mathrm{p}<.001)$. Train, police and fire service employees were also similar in age, with only schoolteachers reflecting a mean age significantly greater than that of train drivers $(\mathrm{p}<.001)$. Similar weekly workloads were evident for all occupations except the librarians, who were found to have a significantly lower workload in comparison to all other occupations $(\mathrm{p}<.001)$. However, a more valid and established measure of workload was also available

Table 2: Correlation Matrix for Warr's [2] factors.

\begin{tabular}{|c|c|c|c|c|c|c|c|c|c|c|c|}
\hline & & 'R' & 1 & 2 & 3 & 4 & 5 & 6 & 7 & 8 & 9 \\
\hline 1 & Control & 0.77 & 1 & $.63^{*}$ & $.28^{*}$ & $.51^{* *}$ & $.50^{*}$ & $.41^{* *}$ & $.37 *$ & $.40^{*}$ & $.32^{* *}$ \\
\hline 2 & Skill & 0.82 & & 1 & $.20 *$ & $.70^{* *}$ & $.44^{*}$ & $.35^{* *}$ & $.24^{*}$ & $.34 *$ & $.26^{* *}$ \\
\hline 3 & Workload & 0.87 & & & 1 & $.12^{*}$ & $.36^{*}$ & $.22^{* *}$ & 0.08 & $.22 *$ & $.35^{* *}$ \\
\hline 4 & Variety & 0.8 & & & & 1 & $.36^{*}$ & $.31^{* *}$ & $.17^{*}$ & $.30 *$ & $.30^{* *}$ \\
\hline 5 & Clarity & 0.76 & & & & & 1 & $.47^{* *}$ & $.22^{*}$ & $.37 *$ & $.40^{* *}$ \\
\hline 6 & Contact & 0.76 & & & & & & 1 & $.22^{*}$ & $.37 *$ & $.36^{* *}$ \\
\hline 7 & Money & 0.79 & & & & & & & 1 & $.29 *$ & $.18^{* *}$ \\
\hline 8 & Status & 0.65 & & & & & & & & 1 & $.28^{* *}$ \\
\hline 9 & Physical & 0.83 & & & & & & & & & 1 \\
\hline
\end{tabular}

Note: "R" represents scale reliability. *Significant at $p<.05$. ** Significant at $p<.01$

This raised a question as to whether a more efficient model of the 9 environmental stressors could be formulated. Maximum Likelihood Factor Analysis (MLFA) was performed on the 9 stressors which produced a robust solution of 4 factors (Figure 3 ). The Kaiser-Meyer-Olkin (KMO) measure of sampling adequacy and the Bartlett Test of Sphericity (BTS) were conducted on the data prior to factor extraction to ensure that the characteristics of the data set were suitable for the MLFA to be conducted. KMO analysis yielded an index of 0.84 , and BTS ( $\chi 2=789.33, \mathrm{df}=36, p<0.001)$ was highly significant indicating the data satisfied the psychometric criteria for the factor analysis to be performed based on data distribution characteristics. Following extraction and oblimin rotation, four factors with eigenvalues greater than 1 emerged from analysis of the complete 9 stressors and cumulatively accounted for $62 \%$ of the variance between factors. (Figure 3) from Warr's environmental stressors questionnaire, that is, perceived workload. Analysis of variance revealed no occupational difference for perceived workload [F(4,287)=.35, $\mathrm{p}>.05][35-38]$.

\section{Gender Differences}

Across the 5 occupations, females reported working fewer hours per week than males [T(290)=5.87, p <.001]. Males employees were found to be significantly younger in age then females $(\mathrm{T}(290)=3.16, \mathrm{p}<.01$.

\section{Warr's Environmental Stressors}

Looking at the inter-correlation matrix below, high associations were evident between the various scales of the 9 factors (Table 2, Figure 2).
The new factors were termed as follows:

i. Factor 1 - "Psychosocial Environment" - Interpersonal Contact, Perceived Clarity, Physical Environment and Valued Social Position were termed as such as in the main, these original factors looked at extrinsic, social and physical aspects of the work environment.

ii. Factor 2 - "Financial Return" - Availability of money remained as an independent factor.

iii. Factor 3 - "Job Design" - Perceived Skill Use, Perceived Variety and Perceived Control reflected factors were all similar to those from Hackman \& Oldham's (1976) "Job Characteristics Model" and therefore termed accordingly.

iv. Factor 4 - "Workload" - Perceived workload remained as an independent factor. 


\section{Psychology and Behavioral Science International Journal}

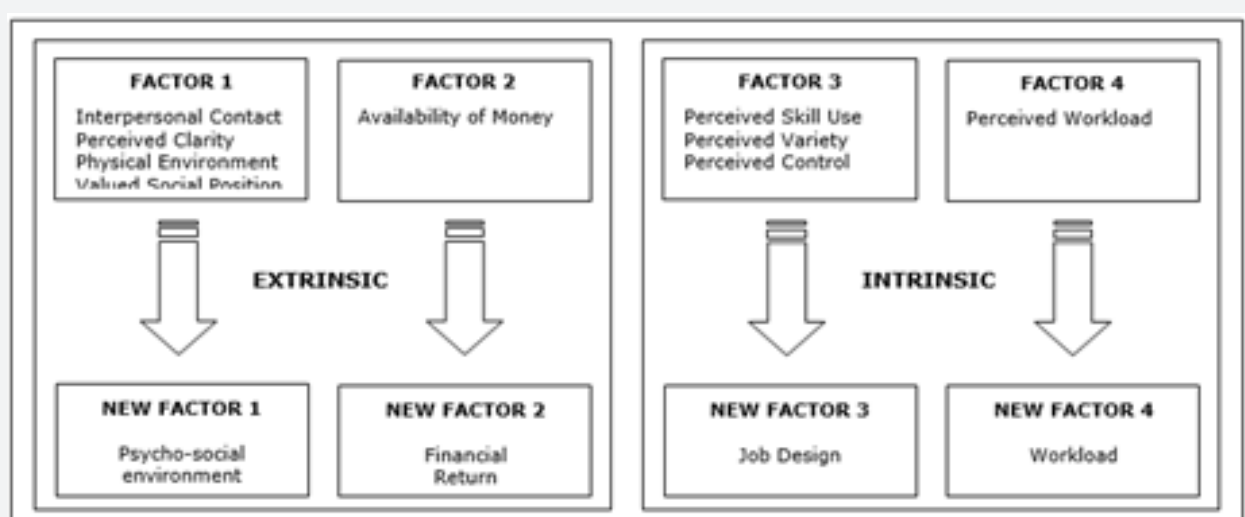

Figure 3: A proposed four factor environmental stressors solution.

Factors 1 and 2 referred to factors that were extrinsic to the job and factors 3 and 4 referred to those that were inherent with the conduct of the job (intrinsic). No differences across occupations were noted for these factors with the exception of "Financial Return" where Police, Fire and Library services reported similar levels of problems associated with pay, but significantly more than train drivers. No gender differences were noted. A four factor solution was accepted for the hypothesis testing stage of this paper [39-40].

\section{Relationships of Interest}

To do this, a correlation matrix was compiled (see Table 3 below) depicting the relationships between these 3 sets of variables: i. Key outcomes of Absenteeism JS and WF conflict.

ii. General mental health

iii. 4 new environmental stressors

Significant correlations were evident between the 3 sets of variables and further regressions were conducted to clarify these relationships. (Table 3)

\section{Predictors of Key Outcomes}

All key outcomes were significantly predicted by the general health of the participant: Absenteeism $(\beta=.17, \mathrm{t}=2.66, \mathrm{p}<.01)$, Job Satisfaction $(\beta=-.23, t=-4.62, p<.001)$ and Work-Family conflict $(\beta=.19, \mathrm{t}=5.22, \mathrm{p}<.001 ;($ Table 4$)$.

Table 3: Depicting correlations between the four new environmental stressors and key outcomes of absenteeism, Job satisfaction, Work-Family conflict and general mental health.

\begin{tabular}{|c|c|c|c|c|c|}
\hline & & \multirow{3}{*}{$\begin{array}{c}\text { General Health } \\
\text { GHQ }\end{array}$} & \multicolumn{3}{|c|}{ Key Outcomes for the Organisation } \\
\hline & & & \multirow{2}{*}{ Absenteeism } & \multirow{2}{*}{ Job Satisfaction } & Work-Family \\
\hline & & & & & Conflict \\
\hline \multirow{4}{*}{ Environmental Stressors } & Psychosocial Environment & $.37^{* *}$ & 0.11 & $-.50^{* *}$ & $.46^{* *}$ \\
\hline & Financial Return & 0.07 & 0.07 & $-.18^{* *}$ & $.17^{* *}$ \\
\hline & Job Design & $.23^{* *}$ & $.14^{*}$ & $-.55^{* *}$ & $.28^{* *}$ \\
\hline & Workload & $.34^{* *}$ & 0.05 & $-.26^{* *}$ & $.53^{* *}$ \\
\hline Health & GHQ & - & $.18^{* *}$ & $-.40^{* *}$ & $.40^{* *}$ \\
\hline
\end{tabular}

${ }^{*}$ Significant at $p<.05 .{ }^{*}$ Significant at $p<.01$

Table 4: Correlational matrix comparing Environmental Stressors and Key Organisational Outcomes.

\begin{tabular}{|c|c|c|c|c|}
\hline & & & \multicolumn{2}{|c|}{ Key Outcomes for the Organisation } \\
\hline & & \multirow{2}{*}{ Absenteeism } & Job Satisfaction & Work-Family \\
\cline { 3 - 5 } & & & & Conflict \\
\hline Environmental Stressors & Psychosocial Environment & 0 & $-.20^{*}$ & $.23^{* *}$ \\
\hline & Financial Return & 0.03 & 0.02 & 0.06 \\
\hline & Job Design & 0.1 & $-.38^{* *}$ & $.37^{* *}$ \\
\hline & Workload & -0.04 & -0.02 & $.19^{* *}$ \\
\hline Health & GHQ & $.17^{* *}$ & $-.23^{* *}$ & 0.63 \\
\hline
\end{tabular}

*Significant at $p<.05 .{ }^{*}$ Significant at $p<.01$

In terms of stressors, the following was evident for the 3 key outcomes:

i. Absenteeism - none of the stressors contributed in explaining any of the variance reflected by Absenteeism 
ii. Job Satisfaction -2 of the 4 stressors, "Psychosocial environment" $(\beta=-.20, t=-3.20, p<.01)$ and "Job Design" $(\beta=-.38, t=$ $-6.71, \mathrm{p}<.001)$, significantly predicted "Job Satisfaction"

iii. Work-Family conflict - significantly predicted by "Psychosocial environment" $(\beta=.23, \mathrm{t}=3.65, \mathrm{p}<.001)$ and "Workload" $(\beta=.37, \mathrm{t}=7.14, \mathrm{p}<.001)$.

The prediction that individuals portraying psychological disturbance (GHQ) would be characterised by the presence of high Table 5: Depicting the number of participants within the two GHQ classifications for each profession and in total.

\begin{tabular}{|c|c|c|c|c|c|c|c|c|c|c|c|c|}
\hline & Police Service & & Fire Service & & Train Drivers & & School Teachers & & \multicolumn{2}{|c|}{ Library Services } & \multicolumn{2}{|c|}{ Total } \\
\hline & $\mathbf{n}$ & $\mathbf{\%}$ & $\mathbf{n}$ & $\mathbf{\%}$ & $\mathbf{n}$ & $\mathbf{\%}$ & $\mathbf{n}$ & $\mathbf{\%}$ & $\mathbf{n}$ & $\mathbf{\%}$ & $\mathbf{n}$ & $\mathbf{\%}$ \\
\hline Healthy & 76 & 65 & 70 & 71 & 9 & 64 & 11 & 61 & 30 & 68 & 196 & 67 \\
\hline $\begin{array}{c}\text { Non- } \\
\text { healthy }\end{array}$ & 41 & 35 & 29 & 29 & 5 & 36 & 7 & 39 & 14 & 32 & 96 & 33 \\
\hline
\end{tabular}

Overall then, two-thirds of all participants were categorised healthy, and a third as experiencing some psychological difficulties. These proportions are broadly consistent for each occupational group, although a higher proportion of schoolteachers absenteeism, low job satisfaction, and greater work to family stress, was tested.

\section{Psychological Health (GHQ) and Occupation}

Based upon the established cut-off of 3 for this questionnaire, participant scores were designated healthy (GHQ $<3$ ) or nonhealthy $(\mathrm{GHQ} \geq 3$ ). The results of this classification are depicted in Table 5 and Figure 4 below.

can be categorised as less healthy (39\%), and that the greatest proportion of healthy employees were the fire fighters. However only 18 questionnaires were obtained from schoolteachers' thus decreasing the impact of the former finding (Figure 4).

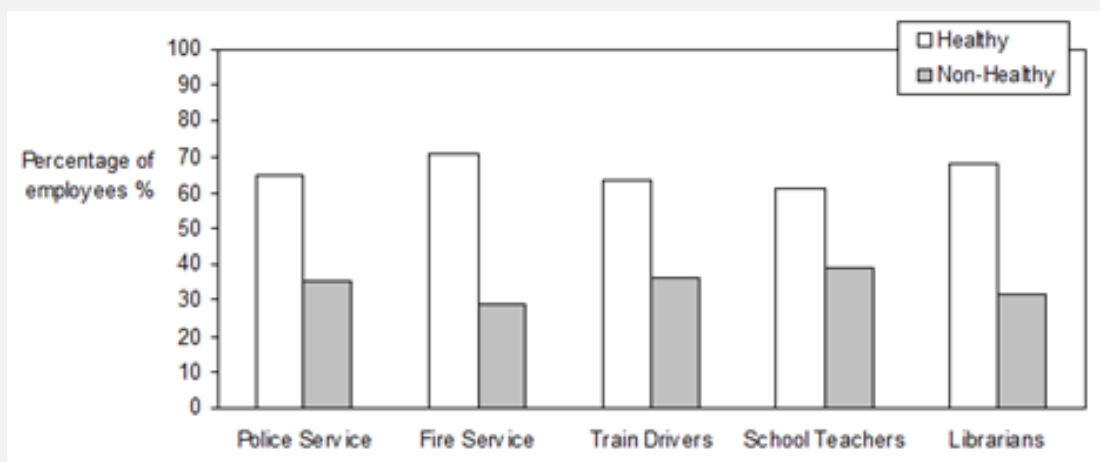

Figure 4: Depicting proportion of healthy and non-healthy individuals by profession.

The likelihood that $33 \%$ of entire cohort were experiencing some form of psychological ill health could be a result of possible floor effects, which may be due to the low cut-off score (3) indicated by the GHQ. Indeed, a score depicting psychological difficulty on three or more of the twelve items that comprise the GHQ will place an individual at or above the threshold score for ill health. However, as the validity of GHQ score has been clearly demonstrated in the literature, the prudent course of action may be to describe GHQ scores at or above the cut-off as denoting possible or probable psychological difficulties.

\section{Predictors of General mental health}

\section{Stressors}

Only 1 of the 4 environmental stressors, "Workload", significantly predicted "General mental health" of the participants: $\beta=$ $.13, \mathrm{t}=2.09, \mathrm{p}<.05$ (Table 6).

\section{Key Outcomes}

All of the key outcomes contributed significantly in predicting General Mental Health of the participants; Absenteeism ( $\beta=$
$.11, \mathrm{t}=2.12, \mathrm{p}<.05)$, Job Satisfaction $(\beta=-.27, \mathrm{t}=-4.22, \mathrm{p}<.001)$ and Work-Family conflict $(\beta=.20, t=3.14, \mathrm{p}<.01)$.

Table 6: Significant predictors of General Mental Health.

\begin{tabular}{|c|c|c|}
\hline Variables & Significant Predictors & General Mental Health \\
\hline \multirow{3}{*}{ Key Outcomes } & Absenteeism & $.11^{*}$ \\
\cline { 2 - 3 } & Job Satisfaction & $-.27^{* *}$ \\
\cline { 2 - 3 } & Work to Family stress & $.20^{* *}$ \\
\hline \multirow{2}{*}{ Stressor } & Workload & $.13^{*}$ \\
\hline 'R' & Correlation & 0.52 \\
\hline
\end{tabular}

${ }^{*}$ Significant at $p<.05 .{ }^{* *}$ Significant at $p<.01$

From the table a negative relationship can be noted between Job Satisfaction and Mental health, in that those with greater job satisfaction are likely to have less of an issue with their Psychological Health.

\section{A Practical Model}

Figure 5 below depicts the aforementioned findings in potentially practical model. It defines the links as established in the above analyses and can be used at a secondary stage once an 
organisation has identified potential problems in their staff. At a secondary stage, this model points to what areas are likely to be affected by the problematic "key outcome" and what stressors the organisation can focus on to begin remedying the issue. (Figure 5)
The finding that financial return did not impact on any of these is consistent with motivation theories in that financial benefits are unlikely to improve the key outcomes for an organisation [41-43].

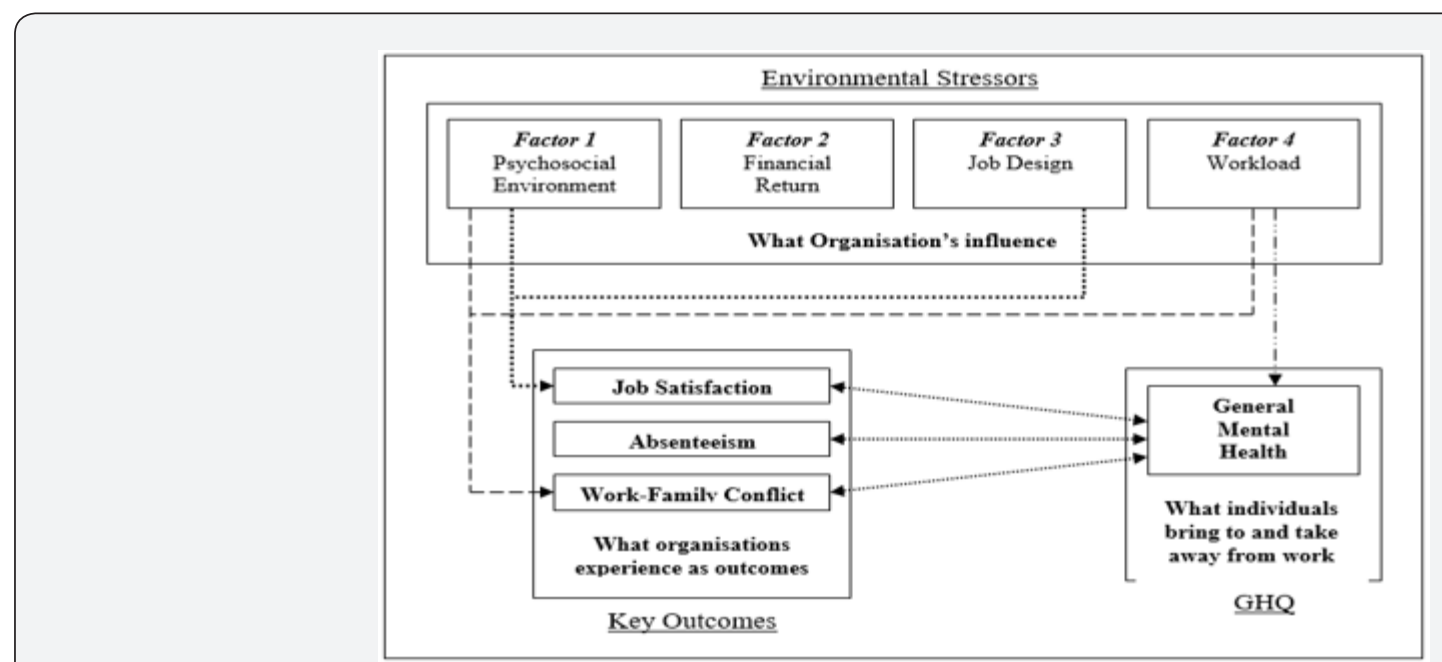

Figure5: A proposed "practical" model.

\section{Discussion}

Overall, the study's hypotheses were generally supported:

i. A highly significant and robust relationship was found between actual workload (hours) and perceived workload as assessed by the Warr questionnaire.

ii. Psychological disturbance was concomitant with the presence of unofficial absenteeism, lower job satisfaction and greater work to family stress. Perceived work stress (as measured by Warr's 9 stressors) was found to predict job satisfaction and work to family stress, although not all 9 variables were predictive in either instance.

iii. Due to the absenteeism data not satisfying basic statistical assumptions for parametric testing (multiple regression) the hypothesis that perceived stress would predict absenteeism could not be tested.

iv. Increased perceived stress (as indicated by 7 of Warr's 9 stressors) was characterised by the presence of psychological disturbance. The 2 stressors that did not discriminate between the presence/absence of psychological disturbance were "perceived variety" and "availability of money".

v. Clear-cut differences in perceived stress were not evident between occupations in the hypothesised hierarchical manner. Rather, a more complex picture emerged where some (but not all) of the 9 stressors discriminated between the employment groups, and in addition, the severity of each stressor was not linked to a particular profession.

\section{Actual vs. Perceived workload}

A significant relationship was evident between perceived workload, and that of the actual numbers of hours the individual spent working. With regards to occupations, librarians reported working fewer hours per week (actual workload) than all other groups, with all other groups conveying similar weekly workloads.

\section{Psychological Disturbance, absenteeism, satisfaction and work-to-family stress}

Psychological disturbance was found to be evident in approximately one-third of all participants with these proportions being broadly consistent for each occupational group. Nevertheless, the likelihood that $33 \%$ of participants were experiencing some form of psychological ill health could be a result of possible floor effects, which, due to its low cut-off score, the GHQ may be susceptible to. Indeed, a score depicting psychological difficulty on three or more items of the twelve that comprise the GHQ would place an individual at or above the threshold score for ill health. However, as the validity of GHQ score has been robustly demonstrated in the past, the prudent course of action may be to describe GHQ scores at or above the cut-off as denoting possible or probable psychological difficulties.

It was found that job satisfaction was predicted by 4 of the 9 stressors: perceived variety; valued social position; perceived clarity and perceived workload. Substantial support for the reliability of these results was obtained from a variety of diagnostic statistics. A possible explanation for these results could stem from the fact that individuals do tend to claim greater satisfaction from aspects such as having a job with a higher valued social position, a lack of pressurised workload with a clear understanding of the job's requirements and job duties with sufficient variety to combat monotony. It was interesting to note that "perceived variety" in a job accounted for $26.8 \%$ of the variance in job satisfaction alone. This may be a valuable area for targeting by employers when considering changes to the work environment, e.g. job redesign. 
The "perceived skill use" stressor was the only predictor of unofficial absenteeism, accounting for a mere $2.6 \%$ variance in this. Nevertheless, this model failed to fulfil even the basics of assumptions for parametric testing and as such the findings in this instance was anecdotal at best.

Three of Warr's stressors: perceived workload, valued social position and perceived clarity were predictive of work-to-family stress, respectively. It would appear evident that a job with a high workload (or perceived workload) is likely to involve a greater deal of work and longer hours, resulting in less "family time". A similar argument could be attributed to work deemed as indicative of a "valued social position", (e.g. General Practitioner, Senior Manager, barrister), where long hours or demanding work is likely to impact upon non-work areas of the individual's life such as the family. Finally, lack of perceived clarity in a job will result in the individual having to do more work to determine exactly (clarify) what needs to be done, which will inevitably lead to increased workload, longer hours and fewer hours spent at home. From these results, it appears work-to-family stress is impacted upon directly by those stressors that instigate pressures on time (perceived workload, valued social position and perceived clarity) and perhaps indirectly by the 4 excluded stressors associated with psychological disturbance (perceived control, perceived skill use, opportunity for interpersonal contact and physical environment) as discussed below, or not at all (perceived variety and availability of money).

Higher perceived stress on 7 of Warr's 9 stressors was indicative of psychological disturbance, with perceived variety and availability of money not differentiating between psychologically disturbed and healthy participants. It is fairly apparent that stress is likely to evoke psychological disturbance and as such support for this hypothesis was unsurprising. Of greater interest is that availability of money and perceived variety did not discriminate between the healthy and non-healthy subgroups. A possible explanation is that availability of money and perceived variety may only impact upon psychological health in combination with other environmental stressors, such as increased financial responsibility or a personal need for occupational development, respectively.

\section{Occupational Differences}

The combined workload factor for the 9 stressors failed to show a difference across the occupational groups, suggesting that although individual stressors may vary across professions (see below), a similar degree of occupational stress is evident in most jobs, whether common sense dictates that they are high or low stress.

4 of Warr's 9 stressors differentiated between the occupational groups in the study: physical environment, perceived variety, valued social position and availability of money. However, there were no trends across occupations for collective stressors. Librarians reported greater problems with their working environments than the police and fire-service. One possibility could stem from the fact that librarians are likely to spend more of their time in an unchanging work environment, whereas the police and fire service have ever-changing work locations. Train drivers on the other hand reported problems with their job variety in comparison to the police and fire service, which indeed was expected, as driving trains usually involves, merely, driving trains; a highly repetitive job. Interestingly, for job variety, librarians did not differ from any other occupational group, although common sense would dictate that their duties may well be the most monotonous. The police and fire service differed on the valued social position they associated with their jobs, with the former reporting greater problems due the perceived public dislike of their work role in comparison to the fire service and librarians. One explanation for this finding was the fact that the police service tends to come under great scrutiny at times of failure and many (police staff) feel they lack public recognition. Indeed, it may be regarded that although librarians' lack recognition for their jobs, the impact of this stressor may be lessened by the lack of any detrimental social characteristics associated with their work.

Train drivers reported greater levels of stress associated with poor pay, in comparison to all other occupational groups except schoolteachers. This finding may be confounded by the well-documented current situation reported in the media, that increases in pay are being demanded by these employees and industrial action has been threatened.

\section{Demographic Differences}

The majority of participants were male (71\%), which reflects the predominant numbers of male workers in the police, fire and train services. For the cohort, males were generally found to be younger than females and also reported working a greater numbers of hours per week (actual workload), although this difference was not evident for the perceived workload. No differences were found between males and females for any of the Warr's stressors, except a borderline difference for "availability of money". Males reported greater problems associated with their pay, than female counterparts, but this difference was very borderline.

\section{Reliability and Validation of Warr's 9 Stressors Ques- tionnaire}

An alpha value of 9015 was determined for Warr's 27-item measure. This high reliability was further supported utilising the split-half method (.8071) and also parallel forms testing (.9015). From assessing the number of factors involved in Warr's measure, exploratory factor analysis dictated 7 in all. However, the utilisation of parallel analysis found support for only 6 factors, with very clear structural coefficients; all items in differing dimensions representing Warr's stressors. Indeed, some of Warr's stressors were combined to form 2 of the (6) factors. These were: factor I (Perceived control, perceived skill uses and perceived variety); factor II (Perceived clarity and Opportunity for interpersonal contact); the remaining 4 stressors were regarded as individual factors.

A possible explanation for the combination of stressors in factor "I" seems to come from the notion that skill use within a job 
usually involves expertise in a variety of job situations, and that this may lead to increased feelings of control. Conversely, an individual would perceive lower control if their work involved little skill use or variety. With regards to Factor II, a lack of clarity in job duties is associated with a greater actual workload and spending more time on completing the job, which would allow lesser opportunities (or time) for interpersonal contact. In summary, Warr's 9 stressors categorised well into a 6-factor solution.

\section{Conclusion}

The study has provided extensive support for the effects of occupational stress upon psychological health and undesirable work outcomes. Participants who reported greater stress levels were likely to have poor job satisfaction, have greater work-family stress and also more unofficial absenteeism in comparison to those reporting lower stress, although the reliability of the latter finding (absenteeism) was questionable due to the violation of several statistical assumptions and would require future validation. Furthermore, individuals with greater perceived stress were more likely to exhibit psychological disturbance.

The methodology employed was mostly successful, with the exception of the absenteeism measure, which attempted to elicit information for participants about unofficial leave they may have undertaken from time to time. Although effort and care were taken to ensure participants that confidentiality and anonymity would be adhered to at all times, the majority of participants failed to respond to this particular section of the questionnaire battery. Indeed, virtually all participants indicated they had never undertaken any unofficial absenteeism, and as such, the results from this measure should be regarded as anecdotal. Other weaknesses were the low number of participants in the train drivers $(n=14)$ and schoolteachers $(n=18)$ groups, and again, sufficient numbers in future studies would ensure that parametric testing was more valid. Thus, specific information ensuring the confidentiality of all participants and addressing their concerns by ensuring that employers would not be proxy to their answers (possibly reiterated prior to the absenteeism section of the questionnaire), or the use of another absenteeism measure is recommended.

In closing, the main aim of this study was to validate Warr's measure and this was achieved with excellent levels of reliability supported by the categorisation of the stressors into 6 factors. Although prudence dictates that replication of this solution is necessary, future research may look towards conducting confirmatory factor analysis, which would utilise data that has been measured based on a 6-factor theory of perceived environmental stress.

\section{References}

1. Warr P (1987) Work, Unemployment and Mental Health. Clarendon Press: Oxford, USA.

2. Warr P (1994) A conceptual framework for the study of work and mental health. Work and Stress 8: 84-97.

3. Cooper CL (1999) The theories of organisational stress. In: Oxford University Press, USA.
4. Ganster DC, Rosen CC (2013) Work Stress and Employee Health: A Multidisciplinary Review. Journal of Management 39(5): 1085-1122.

5. Um MY, Harrison DF (1998) Role stressors, burnout, mediators and job satisfaction: A stress-strain outcome model and an empirical test. Social Work Research 22(2): 100-115.

6. Lamontagne AD, Keegel T, Louie AM, Ostry A, Landsbergis PA (2008) A systematic review of the job-stress intervention evaluation literature, 1990-2005. Int J Occup Environ Health 13(3): 268-280.

7. Warr P (1991) Psychology at work. Penguin: London.

8. Ezoe S, Morimoto K (1994) Quantitative assessment of stressors and stress reaction: a review. Journal of Industrial Health 36: 397-405.

9. Barley S, Knight D (1992) Toward a cultural theory of stress complaints. Research in Organisational Behaviour 14: 1-48.

10. Theorell T, Hammarström A, Aronsson G, Bendz LT, Grape T, et al. (2015) A systematic review including meta-analysis of work environment and depressive symptoms. BMC Public Health 15: 738.

11. Elkin A, Rosch P (1990) Promoting mental health at the workplace: the prevention side of stress management. Occup Med: State of the Art Review 5: 739-754.

12. Sigman A (1992) The state of corporate health care. Personnel Management, pp. 24-31.

13. Eysenck MW, Saddiq MS (in prep.). Unpublished undergraduate dissertation.

14. Tennant C (2001) Work-related stress and depressive disorders. Journal of Psychosomatic Research 51: 697-704.

15. Goldberg D (1992) General health questionnaire, UK.

16. Cieslak R, Shoji K, Douglas A, Melville E, Luszczynska A, et al. (2014) A meta-analysis of the relationship between job burnout and secondary traumatic stress among workers with indirect exposure to trauma. Psychol Serv 11(1): 75-86.

17. Fletcher B (1988) The epidemiology of occupational stress. In: C L Cooper, R Payne (Eds), Causes, Coping and Consequences of Stress at Work, New York, pp. 3-50.

18. Alarcon GM (2011) A meta-analysis of burnout with job demands, resources, and attitudes. Journal of Vocational Behavior 79 (2): 549-562.

19. Zani B, Pietrantoni L (2000) Antecedents and consequences of burnout in hospital employees. Bollettino di Psicologia Applicata 231(47): 35-43.

20. Holder JC, Vaux A (1998) African American professionals: Coping with occupational stress in predominantly White work environments. Journal of Vocational Behaviour 53(3): 315-333.

21. Schonfield IS (2000) An updated look at depressive symptoms and job satisfaction in first-year women teachers. Journal of Occupational and Organizational Psychology 73(3): 363-371.

22. Schaefer JA, Moos RH (1994) Relationship, task and system stressors in the health care workplace. Journal of Community and Applied Social Psychology 3(4): 285-298.

23. Guppy A, Rick J (1996) The influences of gender and grade on perceived work stress and job satisfaction in white collar employees. Work and Stress 10(2): 154-164.

24. Ulleberg P, Rundmo T (1997) Job stress, social support, job satisfaction and absenteeism among offshore oil personnel. Work and Stress 11(3): 215-228.

25. Miles AK (2001) The ergonomics and organizational stress relationship. Dissertation Abstracts International Section A: Humanities and Social Sciences 61(11): 4458. 
26. Naubauer PJ (1994) The impact of stress, hardiness, home and work environment on job satisfaction, illness, and absenteeism in critical care nurses. Medical Psychotherapy: An International Journal 5: 109122.

27. Stansfeld S, Head J, Ferrie J (2000) Short-term disability, sickness absence, and social gradients in the Whitehall II study. Int J Law Psychiatry 22(5-6): 425-439.

28. Vasse RM, Nijhuis F J N, Kok G (1998) Associations between work stress, alcohol consumption and sickness absence. Addiction, 93(2): 231-241.

29. Jacobson BH, Aldana SG, Goetzel R Z, Vardell K D (1996) The relationship between perceived stress and self-reported illness-related absenteeism. Am J Health Promot 11(1): 54-61.

30. Burke R J, Greenglass E R (2001) Hospital restructuring stressors, work-family concerns and psychological well-being amongst nursing staff. Community, Work and Family 4 (1): 49-62.

31. Higgins CA, Duxbury LE, Irving RH (1992) Work-family conflict in the dual-career family. Organizational Behaviour and Human Decision Processes 51: 51-75.

32. Carlson DS, Kacmar KM, Williams LJ (2000) Construction and Initial Validation of a Multidimensional Measure of Work-Family Conflict. Journal of Vocational Behaviour 56: 249-276.

33. Goldberg D, Williams P (1988) A users guide to the General Health Questionnaire, UK.

This work is licensed under Creative Commons Attribution 4.0 License

DOI: 10.19080/PBSIJ.2019.11.555809
34. Price JL, Mueller CW (1981) Professional Turnover: The case of nurses. In: SP Medical \& Scientific Books, New York.

35. Bowerman, O’Connell (1990) In: AP Field (Eds.) (2000) Discovering Statistics using SPSS for windows: advanced techniques for beginners. London.

36. Field AP (2000) Discovering Statistics using SPSS for windows: advanced techniques for beginners, London, UK.

37. French J Caplan, R Harrison V (1982) The mechanisms of job stress and strain. England, UK.

38. Kerr JH, Vos MC (1994) Employee fitness programmes, absenteeism and general well-being. Work and Stress 7(2): 179-190.

39. McGrath J (1976) Stress and behaviour in organisations. In M Dunnette (Ed.), Handbook of industrial and organizational psychology, Chicago, pp. 1351-1395.

40. Michie S (1996) Reducing absenteeism by stress management: Valuation of a stress counselling service. Work and Stress 10(4): 367-372.

41. Sethi A, Schuler R (1984) Handbook of organisational stress: coping strategies, Cambridge.

42. Unden AL (1996) Social support at work and its relationship to absenteeism. Work and Stress, 10(1): 46-61.

43. Wright (1997) In: (Eds.) AP Field (2000) Discovering Statistics using SPSS for windows: advanced techniques for beginners. Sage, London.

\section{Your next submission with Juniper Publishers will reach you the below assets}

- Quality Editorial service

- Swift Peer Review

- Reprints availability

- E-prints Service

- Manuscript Podcast for convenient understanding

- Global attainment for your research

- Manuscript accessibility in different formats

( Pdf, E-pub, Full Text, Audio)

- Unceasing customer service

Track the below URL for one-step submission https://juniperpublishers.com/online-submission.php 